\title{
EFFICACY OF PHYSIOTHERAPY IN IMPROVING THE RANGE OF MOTION OF ELBOW AFTER THE TREATMENT OF PEDIATRIC SUPRACONDYLAR HUMERAL FRACTURE
}

\author{
Jha $S C^{1^{*}}$, Shakya $P^{2}$, Baral $P^{3}$
}

\section{Affiliation}

1. Lecturer, Department of Orthopedic, Birat Medical College \& Teaching Hospital.

2. Post doc fellow, Kyorin University, Japan

3. Assistant Professor, Department of Orthopedics, B.P. Koirala Institute of Health Sciences, Dharan.

\section{ARTICLE INFO}

\section{Article History}

\author{
Received : 4 April, 2018 \\ Accepted : 10 August, 2018 \\ Published : 31 August, 2018
}

(C) Authors retain copyright and grant the journal right of first publication with the work simultaneously licensed under Creative Commons Attribution License CC - BY 4.0 that allows others to share the work with an acknowledgment of the work's authorship and initial publication in this journal.

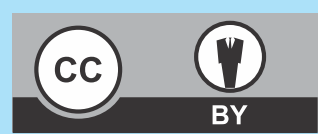

\section{ORA 70}

DOI: $\underline{\text { http://dx.doi.org/10.3126/bjhs.v3i2.20940 }}$

* Corresponding Author

Dr Subash Chandra Jha Lecturer

Department of Orhopedic Birat Medical College and Teaching Hospital Email: subash.jha@gmail.com ORCID: https://orcid.org/0000-0002-0280-2221

\section{Citation}

Jha SC, Shakya P, Baral P. Efficacy of Physiotherapy in Improving the Range of Motion of Elbow after the Treatment of Pediatric Supracondylar Humeral Fracture. BJHS 2018;3(2)6: 432-436.

\section{ABSTRACT \\ Introduction}

Temporary stiffness of elbow range of motion (ROM) after treatment of supracondylar humeralfracturein children is often a parental concern.

\section{Objectives}

We examined the role of physiotherapy in improving the elbow ROM in management of supracondylar humeral fracture in children.

\section{Methodology}

Sixty-four patients were randomly divided into intervention and control groups. Then intervention group patients received regular physiotherapy sessions while control group patients were not sent for physiotherapy. We assessed the outcome according to Flynn criteria during their follow-ups at two, six and 12 weeks, after removal of cast/k-wires.

\section{Results}

In intervention group, $77.4 \%$ children had excellent outcome, and in control group, $80.6 \%$ children had excellent outcome. However, we did not find any statistically significant association between physiotherapy and outcome at 12 weeks, after controlling for baseline characteristics in multivariable regression model.

\section{Conclusion}

Children managed by close reduction for uncomplicated supracondylar humeral fracture with immobilization for three weeks regain their functional ROM within 12 weeks of mobilization by themselves, with no added benefit from physiotherapy.

\section{KEYWORDS}

Children, physiotherapy, supracondylar humeral fracture 


\section{INTRODUCTION}

Supracondylar humeral fracture is the most common pediatric fracture around elbow. ${ }^{1,2}$ Post injury elbow stiffness is usually not the major concern in case of pediatric patients. ${ }^{3}$ Including physiotherapy in fracture management protocol in case of adult is common practice, however, there is lack of evidence that physiotherapy has any positive impact on functional improvement in children who have sustained musculoskeletal trauma. ${ }^{4}$ Several authors recommend physiotherapy while other reject it totally. ${ }^{1,4,5,6,7,8,9}$ Most common parental concern is "How long will it take for the elbow to function normally?" and "Do they have to consult physiotherapist for better outcome?". However, evidence is inconsistent on the role of physiotherapy in management of supracondylar humeral fracture in children. Therefore, we aimed to assess the effectiveness of physiotherapy in improving the post-operative range of motion (ROM)after supracondylar humeral fracturein children.

\section{METHODOLOGY}

We conducted a prospective randomized control trial (RCT) at Dhulikhel hospital, Kathmandu university hospital, from October, 2015 to October 2016.We calculated the sample size using the software G Power version 3, for $95 \%$ power and alpha 0.05. The calculated minimum sample size was 64 with 32 participants in each intervention and control groups. All these patients presented to our hospital with supracondylar humeral fracture were treated by conservative or operative methods. This single center study was approved by the Institutional review committee of our center and was registered at clinicaltrial.gov.in.

The inclusion criteria for joining the study were age between 5-12 years; with isolated supracondylar humeral fracture (Gartland I, II, III) (Figure 1); managed by close reduction (CR) and above elbow slab (conservative) or CR and percutaneous fixation with Kirschner wire (k-wire) (operative); in a mentally sound child after receiving informed written consent to participate in the study from guardian of child. Patients were excluded from the study if they were less than 5 or more than 12 years of age; had open fracture, or required open reduction (OR) or had polytrauma or multiple fractures; had delayed developmental milestones or cannot communicate in Nepali language or the presentation to hospital was at-least after 1 week of fracture.

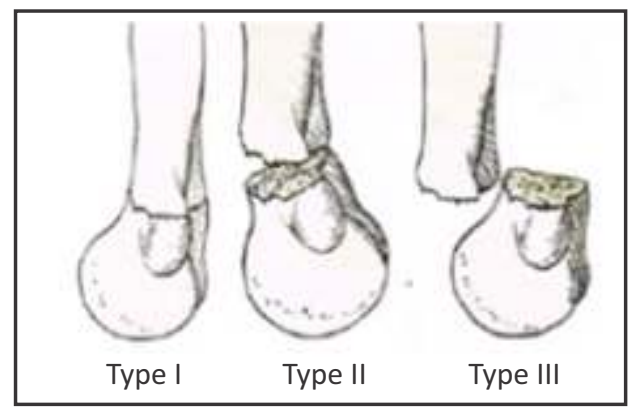

Figure 1: Gartland classification of supracondylar humeral fracture
After 3 weeks of immobilization the above elbow slab and/or K-wires were removed and patients fulfilling the inclusion criteria were randomly divided into intervention and control groups, by an independent assistant other than doctor in the out-patient clinic by simple randomization method. Intervention group children were sent for regular physiotherapy sessions at hospital based physiotherapy department involving passive as well as active ROM exercises as per protocol. Each child was called for regular physiotherapy sessions at every 2-3 days interval for first 2-3 weeks till 10 to 120 degree of ROM was achieved that in the injured elbow. Then onwards children were taught home exercises and were asked for follow-up only if required. While control group patients were not sent for physiotherapy, rather, counselled by the attending orthopedic surgeon and encourage to perform active guarded ROM of elbow for next couple of weeks followed by active normal daily life activities without any extra precautions at child convenience, but passive ROM stretching was discouraged.

Children were followed at 5, 9 and 15 weeks post-surgery and elbow ROM was assessed on each visit and documented according to Flynn's criteria ${ }^{10}$ (Figure 2 ) by surgeon other than the primary investigator. At final follow up, at 12 weeks post removal of slab or k-wires, primary investigator did the final assessment of outcome. Fractures were classified by treating surgeon based on the Gartland system ${ }^{8}$ of pediatric supracondylar humeral fracture classification. Type I fractures are those that were undisplaced; type II fractures were displaced with limited cortical contact and type III fractures were displaced with essentially no cortical contact. Type I fractures were managed by the above elbow slab/cast whereas type II and III were managed by CR and percutaneous k-wires fixation with above elbow splint. Our standard practice after supracondylar fracture included 3 weeks of immobilization in cast/slab, and weekly assessment for loss of reduction by doing plain radiograph of fractured elbow in antero-posterior and lateral views, along with pin-site dressing in case of operated patients. Regardless of type of fracture or treatment received slab/cast or k-wires were removed after 3 weeks.

Elbow ROM was checked with a goniometer ${ }^{8}$ at the day of slab/cast removal, followed by 2, 6 and 12 weeks interval. For measuring flexion and extension, the goniometer was centered at the distal humerus to approximate the axis of elbow flexion extension. The arms of the goniometer were aligned parallel to the axis of the humerus and forearm,

$\begin{array}{lll}\text { Results } & \text { Rating } & \begin{array}{l}\text { Functional Factor: } \\ \text { Motion Loss } \\ \text { (Degrees) }\end{array} \\ \text { Satisfactory } & \text { Excellent } & 0-5 \\ & \text { Good } & 5-10 \\ & \text { Fair } & 10-15 \\ \text { Unsatisfactory } & \text { Poor } & >15\end{array}$

Figure 2: Flynn's criteria 
while arm resting on the table. All the measurements were performed by orthopedic surgeon and recorded as per Flynn's criteria on each follow-up.

We conducted descriptive analysis to compare the baseline characteristics and outcome at 12 weeks after the cast removal. We did it by conducting independent sample t-test for continuous variable and Chi-squared test for categorical variables. We used multi variable logistic regression model to examine the association of physiotherapy with the outcome at 12 weeks after the cast removal. In this model, we controlled for age, sex, type of fracture (Gartland types), and type of procedure. Lastly, we conducted Generalized Estimation Equations (GEE) analysis to examine the efficacy of physiotherapy on the outcome (elbow ROM/Flynn's criteria). For GEE, we included the follow up time points at 2 weeks, 6 weeks and 12 weeks after the cast removal. For both multivariable logistic regression and GEE analyses, we dichotomised the outcome variable (elbow ROM/Flynn's criteria) into Excellent / Good and Fair / Poor.
Intervention group children had mean age of 7.8 years (SD 2.3) compared to 7.5 years (SD 2.2) in control group ( $p=0.509)$. Intervention group had $59.4 \%$ male children compared to $40.6 \%$ in control group ( $p=0.614$ ). About $44 \%$ of children in intervention group had Type III fracture compared to $40.6 \%$ in control group ( $p=0.949$ ). About $78 \%$ children were treated operatively in the intervention group compared to $75 \%$ in control group $(p=0.768)$. All the comparisons were not statistically significant.

\section{Outcome at 12 weeks}

Table 2 presents the comparison of outcome (elbow ROM/Flynn's criteria) at 12 weeks between intervention $(\mathrm{N}=32$ ) and control groups ( $\mathrm{N}=32$ ). In control group, $78.1 \%$ children had excellent outcome, $15.6 \%$ had good outcome and $6.3 \%$ had fair outcome. In intervention group, $75.0 \%$ children had excellent outcome, $21.9 \%$ had good outcome and $3.1 \%$ had fair outcome. None of the children in both groups had poor outcome. However, this comparison was not statistically significant $(p=0.709)$

Table 1: Baseline characteristics between the intervention and comparison groups

\section{No physiotherapy group ( $\mathrm{N}=32$ ) Physiotherapy group ( $\mathrm{N}=32$ )}

\begin{tabular}{|c|c|c|c|c|c|c|c|c|c|}
\hline Variables & $\mathbf{N}$ & Mean & $\%$ & SD & $\mathbf{n}$ & Mean & $\%$ & SD & p-value \\
\hline Age & & 7.5 & & 2.2 & & 7.8 & & 2.3 & 0.509 \\
\hline \multicolumn{10}{|l|}{ Sex } \\
\hline Male & 17 & & 53.1 & & 19 & & 59.4 & & 0.614 \\
\hline Female & 15 & & 46.9 & & 13 & & 40.6 & & \\
\hline \multicolumn{10}{|l|}{$\begin{array}{l}\text { Gartland } \\
\text { fracture type }\end{array}$} \\
\hline I & 8 & & 25.0 & & 7 & & 21.9 & & 0.949 \\
\hline II & 11 & & 34.4 & & 11 & & 34.4 & & \\
\hline III & 13 & & 40.6 & & 14 & & 43.7 & & \\
\hline \multicolumn{10}{|c|}{ Type of procedures } \\
\hline Operative & 24 & & 75.0 & & 25 & & 78.1 & & 0.768 \\
\hline Conservative & 8 & & 25.0 & & 7 & & 21.9 & & \\
\hline
\end{tabular}

We set the statistical significance at $p<0.05$. We conducted all the analyses using STATA software, version 13

\section{RESULTS}

\section{Descriptive characteristics}

Table 1 presents the comparison of baseline characteristics between intervention ( $\mathrm{N}=32$ ) and control groups $(\mathrm{N}=32)$.

\section{Association of physiotherapy with outcome at 12 weeks}

Table 3 shows the results of multi variable logistic regression analysis. We did not find any statistically significant association between physiotherapy and outcome at 12 weeks, after controlling for baseline characteristics (Adjusted odds ratio/AOR=2.13, 95\% Cl 0.17-26.29).

Table 2: Outcomes at 12 weeks after cast removal

\section{No physiotherapy group ( $\mathrm{N}=32)$}

Variable

Flynn criteria

(elbow ROM) n

$\%$

78.1

15.6

6.3
Physiotherapy group (N=32)

n

$\%$

p-value

$\begin{array}{llllll}\text { Excellent } & 25 & 78.1 & 24 & 75.0 & 0.709 \\ \text { Good } & 5 & 15.6 & 7 & 21.9 & \\ \text { Fair } & 2 & 6.3 & 1 & 3.1 & \end{array}$


Table 3: Multivariable logistic regression: Association of physiotherapy with outcome at 12 wks

Elbow ROM/Flynn's criteria

Variable ${ }^{1,2}$ AOR
Physiotherapy

No

Yes
2.13

26.29

0.554
${ }^{1}$ Adjusted odds ratio

${ }^{2}$ Adjusted by age, sex, type of fracture (Gartland types) and type of procedure

\section{Efficacy of physiotherapy on outcome (elbow ROM/ Flynn's criteria)}

Table 4 shows the results of GEE analysis. When controlling for follow-up visits at two, six and 12 weeks after cast removal, we did not find any statistically significant difference on outcome between intervention and control groups $(A O R=1.17,95 \% \mathrm{Cl} 0.46-2.98)$.

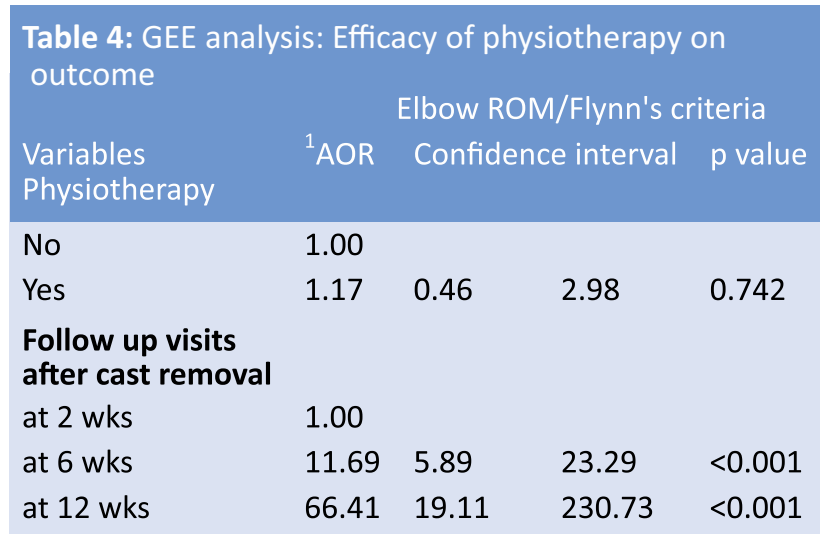

${ }^{1}$ Adjusted odds ratio

\section{DISCUSSION}

The importance of early mobilization of joints to prevent stiffness after treatment of fractures in adults is a widely held view. ${ }^{11,12}$ Active role of physiotherapy in management of adult fractures has been accepted widely. ${ }^{13,} 14,15,16$ Immobilization of elbow in children also has risk of stiffness but usually are temporary and demonstrates no benefit to a formal physiotherapy program. ${ }^{1,4,8}$ The average duration for functional recovery of elbow ROM has been debatable in literature. Keppler et al. ${ }^{4}$ in their prospective RCT conducted in 62 patients of pediatric supracondylar humeral fracture, managed with OR and k-wires fixation demonstrated that children receiving physiotherapy achieved a more rapid return of a normal or near normal elbow ROM at 12 weeks after trauma than the children not receiving physiotherapy. The end result however was not changed at 1 year after trauma by physiotherapy. Spencer et al. ${ }^{7}$ in their prospective longitudinal study in 375 pediatric supracondylar humeral fractures, concluded that greatest increase in axis of motion were observed within first month after cast removal, with progressive improvement for up-to 48 weeks after the injury. None of their patients were sent for physiotherapy for elbow ROM exercises. Zoints et al. ${ }^{17}$ in a retrospective review of 63 patients, surgically treated for pediatric supracondylar humeral fracture showed progressive recovery of elbow ROM over a period of 52 weeks.

In a similar study by Schmale et al. ${ }^{1}$ they noticed ASK-P (Activities scale for kids- performance version) score were significantly better in the no physiotherapy group at 9 and 15 weeks after injury ( $p=0.02$ and 0.01 , respectively) but the difference at 27 weeks was not significant. There were no difference between groups with respect to performance of activities of daily living or time to return to sports. Anxiety at 9 weeks was associated with worse ASK-P score at 9 and 15 weeks in the physiotherapy group and with better ASK-P scores in the no physiotherapy group at these time points $(p=0.01$ and 0.02 , respectively). There were no difference between the groups with respect to elbow motion in the injured arm at any time. They also postulated that severity of injury has no impact on function or elbow motion in either the physiotherapy or the no physiotherapy group.

In most of the studies, the immobilization period was prolonged till 4-5 weeks which may have caused longer duration for recovery of ROM. ${ }^{4,7}$ In our study we only immobilized for 3 weeks in either of groups followed by progressive encouragement of ROM which resulted in excellent outcome at around 15 weeks post-operative in both groups in majority of patients. We also assume that children included in our study were mostly from low socioeconomic background and are more involved in daily household activities from early period, as compared to western society, which may have contributed for early recovery in ROM. However, we do not have any supportive evidence for this hypothesis. Moreover in contrast to Morrey $^{18}$ and King et al. ${ }^{19}$ in our study the type of fracture and the treatment received barely influenced the outcome of fracture accounting that the reduction is optimal and done in closed fashion.

An optimal post-operative program is essential to achieve the best possible results. Children urge for motion is particularly evident between 5 and 10 years, so no joint mobilization measures are necessary in this age group, they move their elbow joint until pain ensures. ${ }^{20}$ As suggested by Minkowitz et al. ${ }^{5}$ and Mclntyre et al. ${ }^{21}$ general practice of 5-6 weeks post-operative immobilization period can be reduced to 3 weeks, as in our study, so that rapid restoration of ROM of elbow can be achieved. Active exercise are more helpful in regaining elbow motion and passive stretching should be discouraged. ${ }^{21}$

\section{CONCLUSION}

There is no added advantage of physiotherapy for improving functional outcome in management of uncomplicated supracondylar humeral fracture in pediatric age. And, it may take upto 12 weeks period for the child to regain his/ her ROM for functional activities of daily living considering the period of immobilization is not more than 3 weeks. 


\section{RECOMMENDATION}

We don't recommend supervised physiotherapy for functional recovery in case of uncomplicated pediatric supracondylar fracture of humerus.

\section{LIMITATION}

We assumed our physiotherapy program to be optimal, the therapist may have been unduly aggressive or unduly conservative in their work with the patient. Second, the sample size in both the control and intervention group were small with lack of long-term follow-up.

\section{ACKNOWLEDGEMENT}

The authors declare that there are no conflicts of interest in relation to the article. The manuscript submitted does not contain information about medical device(s)/drug(s). No funds were received in support of this work.

\section{FINANCIALDISCLOSURE}

\section{None}

\section{REFERENCES}

1. Schmale GA, Mazer S, Mercer LD, et al. Lack of benefit of physical therapy on function following supracondylar humeral fracture. J Bone Joint Surg Am. 2014;96:944-950.

2. Cheng JC, Lam TP, Shen WY. Closed reduction and percutaneous pinning for type III displaced supracondylar fractures of the humerus in children. J Orthop Trauma. 1995;9:511-515.

3. Herring JA. Upper extremity injuries. In: Herring JA, ed. Tachdjian's Pediatric Orthopaedics Philadelphia, PA: W. B. Saunders Co;2002: 2115-2250.

4. P, Salem K, Schwarting B, et al. The effectiveness of physiotherapy after operative treatment of supracondylar humeral fracture in children. J PediatrOrthop. 2005;25:314-316.

5. Minkowitz B, Busch MT. Supracondylar humerus fractures. Current trends and controversies. OrthopClin North Am. 1994;25:581-594.

6. Paradis $G$, Lavallee P, Gagnon N, et al. Supracondylar fractures of the humerus in children. Technique and results of crossed percutaneous k-wire fixation. ClinOrthop. 1993;231-237.

7. Spencer $\mathrm{HT}$, Wong $\mathrm{M}$, Fong $\mathrm{YJ}$, et al. Prospective longitudinal evaluation of elbow motion following pediatric supracondylar humeral fracture. J Bone Joint Surg Am. 2010;92:904-910.

8. Wang $\mathrm{YL}$, Chang WN, Hsu CJ, et al. The recovery of elbow range of motion after treatment of supracondylar and lateral condylar fracture of the distal humerus in children. J Orthop Trauma. 2009;23:120-125.

9. Blount W. Fractures in children. Baltimore: William and Wilkins1955

10. Flynn JC, Matthews JG, Benoit RL. Blind pinning of displaced supracondylar fractures of the humerus in children. Sixteen years' experience with long-term follow-up. J Bone Joint Surg Am 1974;56: 263-272.
11. Helfet DL, Schmeling GJ. Bicondylar intraarticular fractures of the distal humerus in adults. ClinOrthop Relat Res. 1993;292:26-36.

12. Coppola SM, Collins SM. Is physical therapy more beneficial than unsupervised home exercise in treatment of post surgical knee disorders? A systematic review. Knee. 2009;16:171-175.

13. Young P. A short history of the chartered society of physiotherapy. Physiotherapy. 1969;55:271-278.

14. Handoll HH, Sherrington C, Mak JC. Interventions for improving mobility after hip fracture surgery in adults. Cochrane Database Syst Rev. 2011 Mar 16.

15. Handoll HH, Madhok R, Howe TE. Rehabilitation for distal radial fractures in adults. Cochrane Database Syst Rev. 2006. Updated 2015.

16. Dias JJ, Wray CC, Jones JM, et al. The value of early mobilization in the treatment of colles' fractures. J Bone Joint Surg Br. 1987;69:463-467.

17. Zionts LE, Woodson CJ, Manjra N, et al. Time of return of elbow motion after percutaneous pinning of pediatric supracondylar humerus fractures. ClinOrthopRelat Res. 2009;467:2007-2010.

18. Morrey BF. The posttraumatic stiff elbow. ClinOrthopRelat Res. 2005;431:26-35.

19. King GJ, Faber KJ. Posttraumatic elbow stiffness. OrthopClin North Am. 2000;31:129-143.

20. Remschmidt H. Lehrbuch der Kinderheilkunde. In: Schulte FJ, Spranger J, eds. Wachstum Und Entwicklung. Stuttgart, New York: Fischer;1988:5-32.

21. McIntyre W. Supracondylar fractures of the humerus. In: Letts MR, ed. Management of pediatric fractures. New York City, NY: Churchill Livingstone.1994:194. 